\title{
Decreased expression of SorCS1 in colorectal cancer: An independent predictor of poor prognosis
}

\author{
P. Z. HUANG ${ }^{1, *}$, S. Y. PENG ${ }^{1, *}$, H. C. YU ${ }^{1}$, L. HUANG ${ }^{1}$, Q. YAO ${ }^{2}$, X. L. WANG ${ }^{3}$, S. Y. TAN ${ }^{1}$, J. M. ZHOU ${ }^{1}$, P. N. WANG ${ }^{1}$, A. P. HUANG ${ }^{4,5}$, L. L. BAI ${ }^{3}$, \\ Y.X. LUO ${ }^{1, *}$, M.J. HUANG ${ }^{1, *}$ \\ ${ }^{1}$ Department of Colon and Rectum Surgery, Guangdong Provincial Key Laboratory of Colorectal and Pelvic Floor Disease, The Sixth Affiliated \\ Hospital (Guangdong Gastrointestinal and Anal Hospital), Sun Yat-sen University, Guangzhou, Guangdong, 510655, China; ${ }^{2}$ Department of \\ Coloproctology Surgery, Shenzhen People's Hospital, Shenzhen 518020, China; ${ }^{3}$ Guangdong Provincial Key Laboratory of Colorectal and Pelvic \\ Floor Disease, The Sixth Affiliated Hospital (Guangdong Gastrointestinal and Anal Hospital), Sun Yat-sen University, Guangzhou, Guangdong, \\ 510655, China; ${ }^{4}$ Department of Gastrointestinal Surgery, The First Affiliated Hospital, Sun Yat-sen University, Guangzhou 510080, China; \\ ${ }^{5}$ Laboratory of Surgery, The First Affiliated Hospital, Sun Yat-sen University, Guangzhou 510080, China
}

*Correspondence: hmjin@mail.sysu.edu.cn; luoyx25@mail.sysu.edu.cn

"Contributed equally to this work.

Received February 21, 2019 / Accepted July 10, 2019

\begin{abstract}
Previously, we identified that sortilin related VPS10 domain containing receptor 1 (SorCS1) was hypermethylated in colorectal cancer (CRC) tissues. Here, we aimed to investigate the association between CRC and SorCS1. DNA methylation was determined by methylation-specific polymerase chain reaction (MSP) or quantitative real-time methylation analysis (MethyLight). Colorectal cancer tissue specimens from 239 patients that had undergone surgical treatment were evaluated using immunohistochemistry (IHC) analysis for the expression of SorCS1 and correlated with clinicopathological variables and prognosis. We found that SorCS1 was hypermethylated in CRC cell lines and 67.5\% (27/40) CRC tumor tissues. The loss of SorCS1 mRNA $(\mathrm{p}<0.001)$ and protein expression $(\mathrm{p}=0.033)$ were highly correlated with promoter methylation. In addition, SorCS1 expression was significantly increased in younger patients $(\mathrm{p}=0.006)$, low CEA level $(\mathrm{p}<0.001)$ and $\mathrm{pT} 1-2$ stage $(p=0.005)$. Survival analysis revealed that decreased expression of SorCS1 was an independent factor for predicting the increased risk of recurrence $(\mathrm{p}=0.024)$ and poor overall survival $(\mathrm{p}=0.006)$. Subgroup analysis for CEA level, $\mathrm{pT}$ and $\mathrm{pN}$ classifications showed that SorCS1 retained its stratified significance only in patients with low CEA level, pT3-4 tumors and pN1-2 lymph node status. Our findings suggest that SorCS1 is epigenetically inactivated in a substantial fraction of CRC, and its expression may be a promising prognostic factor in CRC patients.
\end{abstract}

Key words: SorCS1, colorectal cancer, predictor, methylation

Colorectal cancer (CRC) is the third most common cause of cancer mortality worldwide [1]. Despite modest improvements in the systemic therapy over the last two decades, relapse is common among patients with CRC [2]. In recent years, the morbidity and mortality of CRC have increased rapidly in Chinese population [3]. Although patients with an early-stage CRC have a favorable prognosis, a small fraction of these patients will inevitably develop a recurrence after intentionally curative surgery [4]. The poor outcome of certain CRC patients is mainly attributed to late diagnosis and tumor recurrence. Therefore, identifying these patients with inferior prognosis will allow optimized selection of individuals that would benefit from adjuvant therapy. Epigenetic alterations, particularly inactivation of tumor suppressor genes or tumor-related genes through promoter hypermethylation play an important role in the development and progression of human cancers, including CRC [5-7]. Exciting new insights in such novel genes targeted by promoter methylation may help to find alternative approaches for diagnostic and therapeutic evaluation. In order to identify the role of epigenetic alterations in the initiation and progression of CRC, we initially carried out an epigenome-wide analysis of tissues of normal colon mucosa, tubular adenoma and CRC. In this genome-wide survey, we found hundreds of novel methylation alterations during early stages of progression of tubular adenomas to cancer [8].

Hypermethylation of sortilin related VPS10 domain containing receptor 1 (SorCS1) was one of the molecular events discovered through HumanMethylation450 Arrays. SorCS1 has been reported as the first identified member of 
a subgroup of the mammalian Vps10p-domain (Vps10pD) 1 receptor responsible for transporting soluble vacuolar enzymes to the yeast vacuole (the yeast equivalent of the mammalian lysosome) [9]. Information on SorCS1 is still limited and little is known about its cellular and physiological functions. Analysis of SorCS1 in healthy tissues showed that it is most highly expressed in the brain, heart, kidney, pancreatic islets and $\beta$-cells $[10,11]$. Emerging evidence indicated that SorCS1 was related to complex disorders, Type 2 diabetes and Alzheimer's disease [12, 13]. However, the role of SorCS1 in tumor is largely unknown. Using the TCGA (The Cancer Genome Atlas) Dataset, Hua et al. reported that SorCS1 was hypermethylated and downregulated in rectal cancer [14]. Nevertheless, no study has investigated the protein expression and prognostic significance of SorCS1 in human CRCs.

In the present study, we determined the methylation and expression status of SorCS1 in colorectal cancer cell lines and primary colorectal cancer tissue samples. We also analyzed the correlation of SorCS1 expression with clinicopathological variables and outcomes of patients and addressed its prognostic role in CRC.

\section{Patients and methods}

Cell lines. Human CRC cell lines HCT116, SW620, LoVo, RKO, DLD-1 and Caco-2 were purchased from the U.S. National Cancer Institute and cultured by continuous passage in Roswell Park Memorial Institute 1640 (Thermo Fisher, Waltham, Massachusetts, USA) supplemented with $10 \%$ fetal bovine serum and $1 \%$ penicillin and streptomycin. Cells were maintained in a humidified incubator at $37^{\circ} \mathrm{C}$ in $5 \% \mathrm{CO}_{2}$. RNA, DNA and protein were extracted from exponentially growing cells. Some of the cell lines were treated with the DNMT1 inhibitor $(5 \mu \mathrm{M})$ 5-aza-2'-deoxycytidine (5-AZA; Sigma) in the experiments in this study.

Patients and tissue samples. Tissue specimens used in immunohistochemistry (IHC) analysis were obtained from 239 patients treated for sporadic CRC between January 2009 and December 2012 in the Colorectal Surgery Department, the Sixth Affiliated Hospital of Sun Yat-sen University [15]. Both paired tumor and adjacent normal mucosa samples were collected from each patient during the surgery. The inclusion of the patient cohorts included (a) having a distinctive pathologic diagnosis of CRC, (b) having no distant metastasis and none anticancer treatment before surgery, (c) having curative resection of CRC, (d) having suitable formal infixed, paraffin-embedded tissues and frozen tissues, (e) having complete clinicopathologic and follow-up data. Curative resection was defined as removal of all macroscopic tumor masses, absence of microscopic residual tumor, histologically confirmed negative resection margins and extension of lymphadenectomy beyond involved nodes. CRC diagnosis was based on World Health Organization criteria and staged according to the 7th edition tumor-node-metastasis (TNM) classification of the American Joint Committee on Cancer. Tumor location was classified as colon and rectum.

Resected tumors from 198 CRC patients were evaluated for the presence of the most common mutations of the KRAS (codons 12 and 13) and/or BRAF (codon 600) genes.

Follow-up was carried out until April 2017. The median follow-up was 64.87 months (range 1.43 to 98.10 months). Overall survival (OS) was defined as the interval between tumor resection and death; patients alive at the end of followup were censored. Recurrence-free survival was measured from the date of surgery to that of recurrent of metastatic disease occurrence. We then defined early recurrence $(n=33)$ as that diagnosed in the first 24 months after surgery, and late recurrence $(\mathrm{n}=17)$ as that occurred at any time thereafter. There were 40 cancer specific deaths (mean time 31.13 months from treatment) and 199 survivors (mean time to the last follow-up date 70.89 months).

DNA and RNA extraction. DNA and RNA were isolated from the human CRC cell lines, fresh frozen tumor tissues and normal mucosa (QIAamp DNA Mini Kit and Qiazol, respectively) according to the manufacturer's instruction. The total RNA and DNA extracted from all the samples were analyzed for quantity and quality using the NanoDrop spectrophotometer. RNA and DNA extraction were repeated when samples did not meet the manufacturer's recommendations. The samples that were not satisfactory for either quantity or quality during repeat extraction were excluded from the analysis.

SorCS1 methylation analyses. SorCS1 methylation status was assessed by methylation-specific PCR (MSP) and quantitative MSP (MethyLight). Firstly, the DNA was modified with sodium bisulfite for use in methylation specific PCR (MSP) assays as previously described [16]. DNA methylation of $\mathrm{CpG}$ islands was determined by PCR using specific primers for both methylated and unmethylated DNA. Two sets of primers were used to amplify each region of interest: one pair recognized a sequence in which $\mathrm{CpG}$ sites are unmethylated (bisulfite-modified to $\mathrm{UpG}$ ), and the other recognized a sequence in which $\mathrm{CpG}$ sites are methylated (unmodified by bisulfite treatment). MSP was performed in the ProFlex PCR system (Life, Singapore). The reaction system consisted of $1 \mu \mathrm{l}$ forward primer $(20 \mu \mathrm{M}), 1 \mu \mathrm{l}$ reverse primer $(10 \mu \mathrm{M}), 1 \mu \mathrm{l} \mathrm{cDNA}$ template and $10 \mu \mathrm{l}$ Go Tap Green Master mix (Promega). The methylated SorCS1 primers sequences were as follows: methyl-specific forward primer: 5'-TTATAGTCGTTAGCGTAGAGTTCGT-3', reverse primer: 5'-AATAAAAAAAACCCCTAAAAATCGA-3'; unmethylated specific forward primer: 5'-TTTTTTATAGTTGTTAGTGTAGAGTTTGT- ${ }^{\prime}$ ' and reverse primer: 5'-ATAAAAAAAACCCCTAAAAATCAAA-3'. The thermocycler conditions are $94^{\circ} \mathrm{C} \times 15 \mathrm{~min}, 45 \times\left(94^{\circ} \mathrm{C} \times 30 \mathrm{~s}\right.$, $\left.62^{\circ} \mathrm{C} \times 30 \mathrm{~s}, 72^{\circ} \mathrm{C} \times 30 \mathrm{~s}\right), 72^{\circ} \mathrm{C} \times 10 \mathrm{~min}$. All the samples were subjected to at least two independent rounds of sodium bisulfite treatment and MSP assays. Control samples from cells with known methylated and unmethylated SorCS1 were 
included in each MSP assay to confirm the technical success of the assays. The PCR products were visualized by agarose gel electrophoresis and ethidium bromide staining.

Quantitative MSP ("MethyLight") assays were conducted on bisulfite treated DNA following published protocols [16] and performed using LC96 PCR System (Roche). CpGenome Universal Methylated DNA (Millipore, S7821) was used to calculate PMR of each sample. The primers sequences are methyl-specific forward primer: 5'-CGGCGGCGGTTCGT-3', methyl specific reverse primer 5'ACGACCGCTTACCCGAACTA-3'; probe sequence: 5'-CGCGTTCGGTATAAGT-3'

Real-time quantitative PCR analysis. PCR was performed in a final volume of $20 \mu \mathrm{l}$ containing $1 \mu \mathrm{l}$ CDNA, $1 \mu \mathrm{l}$ SorCS1 TaqMan ${ }^{\circledR}$ Gene Expression Assay (Hs00364666_ml, Thermo Fisher) and 2X TaqMan ${ }^{\star}$ Universal Master Mix (Thermo Fisher). Data were normalized to the housekeeping gene GUSB (Hs00939627_m1, Thermo Fisher). All reactions were run in triplicate on an LC96 PCR System (Roche). The relative expression level of SorCS1 mRNA for each sample was calculated as: $\Delta \Delta \mathrm{Ct}($ sample $)=\Delta \mathrm{Ct}$ (sample) $-\Delta \mathrm{Ct}$ (calibrator), where $\Delta \mathrm{Ct}$ (sample) $=\mathrm{Ct}$ (sample) of SorCS1 mRNA - Ct (sample) of GUSB mRNA; $\Delta$ Ct (calibrator) of SorCS1 mRNA = Ct (calibrator) of SorCS1 - Ct (calibrator) of GUSB mRNA. The fold changes in mRNAs were calculated by the equation $2^{-\Delta \Delta C t}$. The calibrator was defined as the sample with the highest Ct value of SorCS1 mRNA (sample with the lowest expression level of SorCS1 mRNA) among all samples.

Immunohistochemistry staining. Formalin-fixed, paraffin-embedded sections of colorectal adenocarcinomas and matched normal colonic mucosa tissues were subjected to immunostaining using a rabbit anti-human SorCS1 polyclonal antibody (HPA011948, Sigma-Aldrich). Briefly, $4 \mu \mathrm{m}$ tissue sections were deparaffinized, rehydrated and subjected to antigen retrieval by Tris- $\mathrm{HCl}(\mathrm{pH} 9.2)$ through microwave at $100^{\circ} \mathrm{C}$ for $30 \mathrm{~min}$. The sections were blocked with goat serum and then incubated with anti-SorCS1 primary antibody (1:100 dilution) overnight at $4{ }^{\circ} \mathrm{C}$. Next, the sections were stained with 3,3'-diaminobenzidine, counterstained with hematoxylin and mounted. The samples were scored according to following criteria: (a) percentage of immunoreactive cells, $1=0-30 \%, 2=>30-70 \%$, $3=>70 \%$; and (b) staining intensity, $0=$ negative, $1=$ weak, $2=$ moderate and $3=$ strong. The final score generated used to score the slide was $(\mathrm{a}) \times(\mathrm{b})$. Each IHC score was independently assessed by two pathologists without prior knowledge of patient data. Differences in scores were discussed by the two pathologists to reach an agreement. A third pathologist would take part in the discussion if necessary. For statistical analysis, IHC scores of $0-3$ were considered low expression, and scores of 4-9 were considered high expression.

Western blot analysis. Western blot analysis was performed as described previously [16]. The membrane was incubated with anti-SorCS1 rabbit polyclonal antibody
(HPA011948, Sigma-Aldrich) and anti-GAPDH antibody (sc-69778, Santa Cruz Biotechnology) (1:2000 for SorCS1 and 1:1000 for GAPDH). Immunoreactive proteins were then visualized by incubating the PVDF membranes with ECL plus detection reagents, followed by imaging of chemiluminescence on an imager (X-ray film-based).

Statistical analysis. Statistical analyses were performed with the SPSS, version 20. Receiver operating characteristic (ROC) curves and area under the curve (AUC) for SorCS1 methylation frequency of primary tissues were constructed on the basis of methylation levels. Associations between SorCS1 expression and clinicopathological variables were evaluated using Chi-Square and Fisher's Exact Tests. Student's t-test was used to compare data of two different groups for normally distributed quantitative data. Univariate and multivariate analyses were also conducted using Cox's proportional hazard model for analyzing prognostic factors. Survival curves were compared with the log-rank test. All statistical tests were two-sided, with significance defined as a p-value of $<0.05$.

\section{Results}

Decreased expression and hypermethylation of SorCS1 in CRC cell lines and tumor tissues. After observing methylated SorCS1 in the colorectal cancers ran on the HumanMethylation 450 arrays, we assessed the methylation status of SorCS1 in a second independent set of CRC cell lines, normal colon mucosa and CRCs using primer sets in promoter region of SorCS1, which had been validated. First, quantitative RT-PCR (qRT-PCR) (Figure 1A) and western blot (Figure 1B) were employed to examine the expression of SorCS1 in 6 colon cancer cell lines. SorCS1 expression was remarkably decreased in RKO, DLD-1, Caco-2 and HCT-116 cell lines compared with SW620 and LoVo cells. SorCS1 methylation status was assessed in the identical panel of cell lines (Figure 1C). The cell lines that carried methylated SorCS1 expressed relatively low mRNA and protein levels of SorCS1 (Figures 1A, 1B). To furtherly substantiate that SorCS1 methylation is primarily responsible for the loss of SorCS1 expression, we treated HCT-116, DLD-1 and SW620 cells with a DNA methyltransferase inhibitor, 5-aza-2'-deoxycytidine, to determine whether demethylation restored SorCS1 expression. As shown in Figure 1D, 5-aza-2'-deoxycytidine reactivated SorCS1 expression in the HCT-116 and DLD-1 as detected by qRT-PCR, while not obvious affecting that in SW620, suggesting that DNA methylation plays a causal role in the SorCS1 loss of expression in CRC. The methylation of SorCS1 after treatment also assessed by MSP and the result is shown in Figure 1E. The methylated and unmethylated PCR products in promoter region of Sorcs 1 are 251 and 254, respectively. To determine whether there was a more consistent relationship between SorCS1 methylation status and expression in primary tumor samples, we analyzed SorCS1 methylation status and mRNA expression in primary 

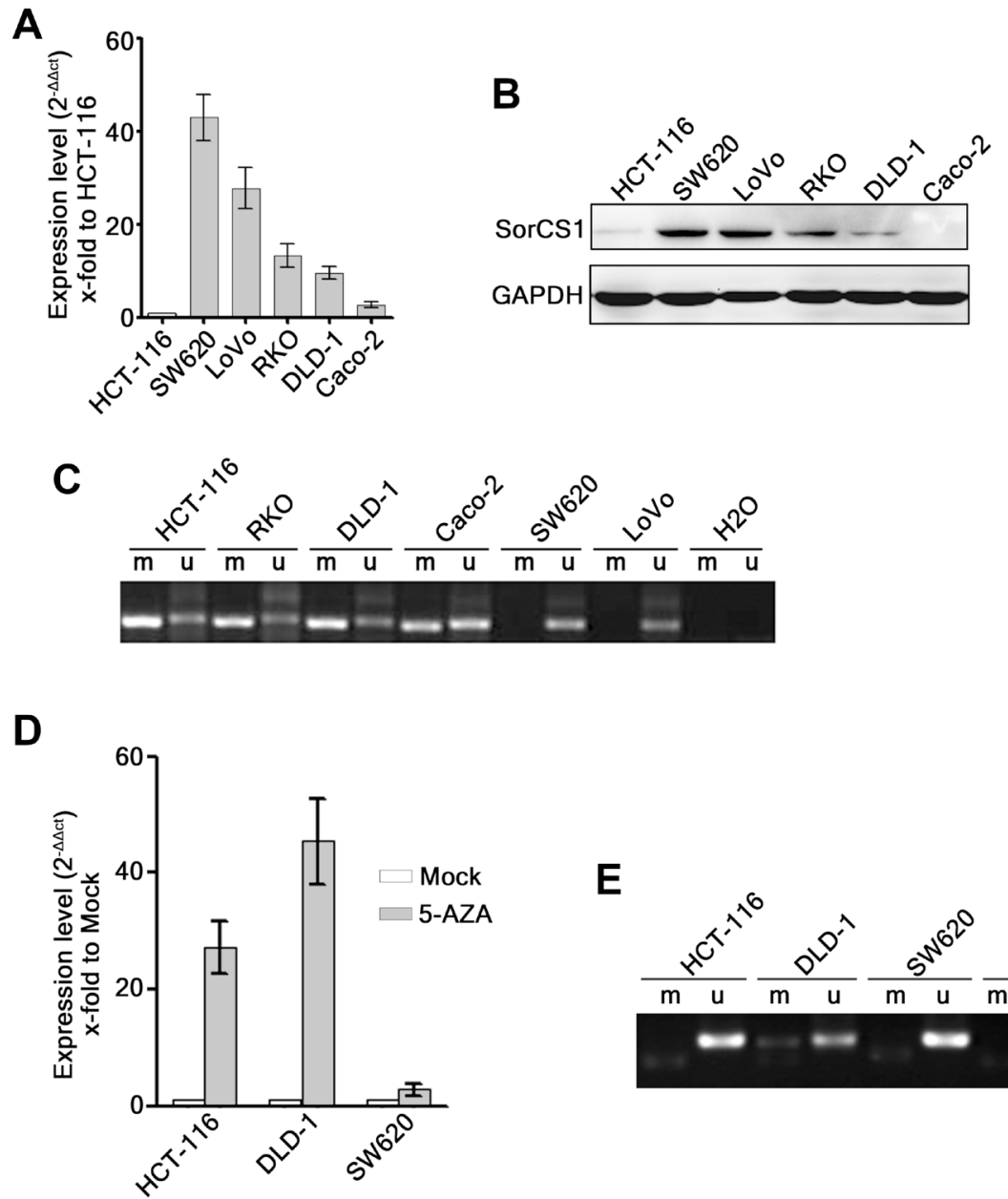

E

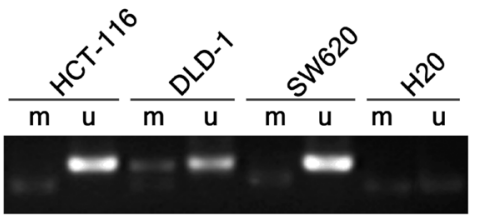

Figure 1. SorCS1 methylation status correlated with reduced mRNA and protein expression in colorectal cancer (CRC) cell lines. As shown by realtime PCR (A) and western blot (B), the expression of SorCS1 was much higher in CRC cell lines SW620 and LoVo. Methylation of SorCS1 was found in CRC cell lines HCT-116, RKO, DLD-1 and Caco-2 but not in SW620 and LoVo through methylation-specific PCR (C). SorCS1 mRNA expression was restored after treatment with 5-AZA (D). Methylation of SorCS1 was found inversed in CRC cell lines HCT-116, DLD-1 and similar in SW620 through methylation-specific PCR (MSP) after treatment with 5-AZA (E). M: methylated; U: unmethylated. Two sets of primers for methylated and unmethylated allele, respectively.

40 pairs of colorectal cancer samples and in adjacent normal colon mucosa. We first established that a Percent of Methylated Reference (PMR) threshold of $20.7 \%$ had a specificity of $\sim 90 \%$ for cancer vs. normal tissue according to ROC analysis and the AUC for this sample set is $0.894(0.828-0.960)$. Using this PMR threshold, we detected SorCS1 promoter methylation in $67.5 \%$ of colorectal cancers $(n=27)$, then the methylation-low and the methylation-high groups were defined through this cut-off value. Using this same PMR threshold, SorCS1 promoter methylation was found in $10.0 \%$ adjacent non-tumor tissues $(\mathrm{n}=4)$ (Figure 2A). Expression data showed that SorCS1 mRNA level was lower in primary CRC tumor tissues versus matched normal mucosa (Figure 2B). Next, we found that SorCS1 expression was inversely correlated with the degree of SorCS1 promoter methylation in tumors (Figure 2C), suggesting that SorCS1 promoter methylation repressed the transcriptional activity of Sorcs1 in CRC.
Immunohistochemistry (IHC) was performed to evaluate SorCS1 protein expression in 239 pairs of CRC tumor tissues and their adjacent normal tissues. In positive samples, SorCS1 protein was expressed predominantly in cellular cytoplasm and membrane, but not in nucleus.

In the malignant tissues, unlike adjacent normal mucosa tissues, the expression area and intensity were both heterogeneous. The expressions of the tumors were divided into four groups according to the immunohistochemical score: negative (staining score 0 ), low (staining score 1-4), intermediate (staining score 5-8) or high (staining score 8-12). For statistical analysis, IHC scores of $0-4$ were considered low expression and scores of 5-12 were considered high expression. Low expression was detected in 135 CRC cases (56.49\%), whereas 236 adjacent normal mucosa tissues (98.74\%) expressed high levels of SorCS1 (Figures 2D-F). When we compared the methylation data with the protein expression, 
difference was observed in CRC samples with lower expression found in the methylation-high group compared to the methylation-low group. (Figures 2D-F, Table 1).

Associations between expression of SORCS1 and clinicopathological variables. We then explored the correlation of SorCS1 protein expression with patients' clinicopathological features. As shown in Table 1, SorCS1 had higher expression in patients with lower serum CEA levels $(\mathrm{p}<0.001)$, younger age $(\mathrm{p}=0.006)$ and earlier local tumor stage ( $\mathrm{pT}$ stage) $(\mathrm{p}=0.005)$. However, SorCS1 expression was not significantly associated with gender $(p=0.080)$, histological grade $(p=0.318)$, histological subtype $(p=0.175)$, nodal status $(p=0.588)$, vessel invasion $(p=0.681)$, perineural invasion $(\mathrm{p}=0.422)$, KRAS status $(\mathrm{p}=0,601)$ and BRAF status $(\mathrm{p}=0.624)$.

Associations between expression of SorCS1 and clinical outcome. To determine whether there is a relationship between SorCS1 and treatment outcomes, we assessed the correlation between SorCS1 expression and survival. Survival curves were constructed by Kaplan-Meier method and compared by the log-rank test. As shown in Figures 3A-B, patients with low SorCS1 expression level had shorter OS $(p=0.004)$ and RFS $(p=0.005)$ than those with high SorCS1 expression level. In univariate analysis, age $(\mathrm{p}<0.001$ and $\mathrm{p}=0.128)$, nodal status $(\mathrm{p}=0.048$ and $\mathrm{p}<0.001)$, and vessel invasion $(\mathrm{p}=0.009$ and $\mathrm{p}=0.022)$ were risk factors for OS and/or RFS (Table 2). With respect to the time to recurrence, the prognostic significance of SorCS1 existed in both early $(\mathrm{p}=0.040)$ and late recurrence $(\mathrm{p}=0.048)$ groups (Figures $3 \mathrm{C}$ and $3 \mathrm{D}$ ). Clinicopathological variables significant on univariate analysis were introduced into a Cox proportional hazard model. Multivariate analysis revealed that the SorCS1 expression was an independent prognostic factor for both OS $(p=0.024)$ and RFS $(p=0.006)$ (Table 3$)$. In addition, age $(p=0.001)$ and vessel invasion $(p=0.008)$ were associated with OS only. Nodal status $(\mathrm{p}=0.001)$ was associated with RFS only.

Furtherly, we examined whether CEA level and tumor stage significantly modified the association of SorCS1 expression with patient survival. We further stratified patients by CEA level, tumor status and nodal status (Figures 4A-F). Stratified analysis indicated that the significance of SorCS1 expression in predicting OS and RFS was retained in the subgroups with CEA $<5 \mathrm{ng} / \mathrm{ml}$ ( $\mathrm{p}=0.014$ and $\mathrm{p}=0.003$, respectively), $\mathrm{pT} 3-4$ stage $(\mathrm{p}=0.014$ and $\mathrm{p}=0.047$, respectively) and $\mathrm{pN} 1-2$ stage ( $p=0.033$ and $p=0.007$, respectively). Nevertheless, OS and RFS were not significantly between SorCS1 high and low groups within patients with CEA $\geq 5 \mathrm{ng} / \mathrm{ml}$ ( $\mathrm{p}=0.685$ and $\mathrm{p}=0.569$, respectively $)$, $\mathrm{T} 1-2(\mathrm{p}=0.433$ and $\mathrm{p}=0.072$, respectively) and $\mathrm{pN} 0(\mathrm{p}=0.058$ and $\mathrm{p}=0.253$, respectively).
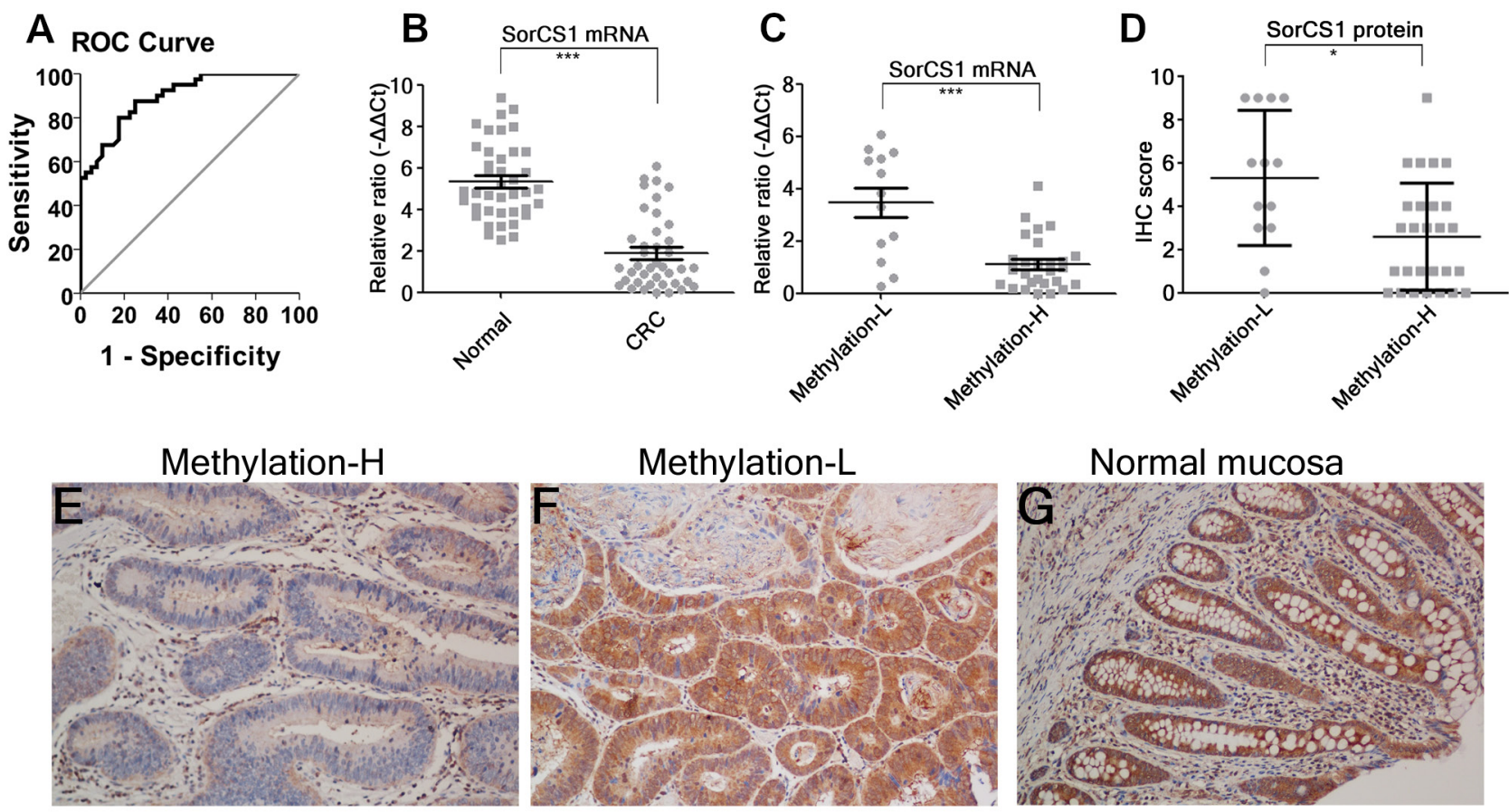

Figure 2. SorCS1 methylation status and expression in colorectal cancer (CRC) tissues. ROC analysis determined the optimal percentage of methylated reference (PMR) for methylated value that detected cancer specific levels of SorCS1 (A). Relative SorCS1 mRNA levels in CRC tumor tissues significantly decreased when compared with those in adjacent normal mucosa by qRT-PCR analysis (B). According to SorCS1 methylation status, CRC tumor tissues with methylation-high expressed lower levels of SorCS1 mRNA than those in methylation-low (C). Immunohistochemistry staining showed that SorCS1 protein expression was significantly downregulated in CRC tumor tissues, especially in tumor tissues with hypermethylation, compared with adjacent normal mucosa $(D-G)$. Original magnification $\times 200,{ }^{* * *} \mathrm{p}<0.001,{ }^{\star} \mathrm{p}<0.05$. 
Table 1. The association of SorCS1 expression with clinicopathological variables.

\begin{tabular}{|c|c|c|c|c|}
\hline \multirow[b]{2}{*}{ Variables } & \multirow[b]{2}{*}{$n=239$} & $\begin{array}{c}\text { SorCS1 } \\
\text { Low }\end{array}$ & $\begin{array}{c}\text { SorCS1 } \\
\text { High }\end{array}$ & \multirow[b]{2}{*}{ p-value } \\
\hline & & $\mathrm{n}=135$ & $\mathrm{n}=104$ & \\
\hline \multicolumn{5}{|l|}{ Age (years) } \\
\hline$\leq 60$ & $107(44.8 \%)$ & 50 & 57 & 0.006 \\
\hline$>60$ & $132(55.2 \%)$ & 85 & 47 & \\
\hline \multicolumn{5}{|l|}{ Gender } \\
\hline Female & $111(46.4 \%)$ & 56 & 55 & 0.080 \\
\hline Male & $128(53.6 \%)$ & 79 & 49 & \\
\hline \multicolumn{5}{|l|}{ CEA (ng/ml) } \\
\hline$<5$ & $172(72.0 \%)$ & 78 & 94 & $<0.001$ \\
\hline$\geq 5$ & $67(28.0 \%)$ & 57 & 10 & \\
\hline \multicolumn{5}{|l|}{ Histological grade } \\
\hline Moderate, High & $193(80.8 \%)$ & 106 & 87 & 0.318 \\
\hline Poor & $46(19.2 \%)$ & 29 & 17 & \\
\hline \multicolumn{5}{|l|}{ Mucinous } \\
\hline No & $208(87.0 \%)$ & 114 & 94 & 0.175 \\
\hline Yes & $31(13.0 \%)$ & 21 & 10 & \\
\hline \multicolumn{5}{|l|}{ Location } \\
\hline Colon & $121(50.6 \%)$ & 66 & 55 & 0.540 \\
\hline Rectum & $118(49.4 \%)$ & 69 & 49 & \\
\hline \multicolumn{5}{|l|}{ Tumor status } \\
\hline $\mathrm{T} 1-2$ & $55(23.0 \%)$ & 22 & 33 & 0.005 \\
\hline $\mathrm{T} 3-4$ & $184(77.0 \%)$ & 113 & 71 & \\
\hline \multicolumn{5}{|l|}{ Nodal status } \\
\hline N0 & $154(64.4 \%)$ & 85 & 69 & 0.588 \\
\hline $\mathrm{N} 1-\mathrm{N} 2$ & $85(35.6 \%)$ & 50 & 35 & \\
\hline \multicolumn{5}{|l|}{ Vessel invasion } \\
\hline No & $221(92.5 \%)$ & 124 & 97 & 0.681 \\
\hline Yes & $18(7.5 \%)$ & 11 & 7 & \\
\hline \multicolumn{5}{|l|}{ Perineural invasion } \\
\hline No & $219(91.6 \%)$ & 122 & 97 & 0.422 \\
\hline Yes & $20(8.4 \%)$ & 13 & 7 & \\
\hline \multicolumn{5}{|c|}{ KRAS status $(n=197)$} \\
\hline Wild type & $125(63.5 \%)$ & 70 & 55 & 0.601 \\
\hline Mutant & $72(36.5 \%)$ & 30 & 28 & \\
\hline \multicolumn{5}{|c|}{ BRAF status $(n=198)$} \\
\hline Wild type & $190(96.0 \%)$ & 102 & 88 & 0.624 \\
\hline Mutant & $8(4.0 \%)$ & 5 & 3 & \\
\hline \multicolumn{5}{|l|}{ Methylation $(n=40)$} \\
\hline High & $27(67.5 \%)$ & 18 & 9 & 0.033 \\
\hline Low & $13(32.5 \%)$ & 4 & 9 & \\
\hline
\end{tabular}

\section{Discussion}

Methylation of SorCS1 had been recognized in our previous study. However, the role of SorCS1 in CRC development remains poorly understood. This study aimed to identify the clinical significance of SorCS1. Our findings showed that expression of SorCS1 was repressed by promoter methylation. In survival analysis, SorCS1 was associated with disease recurrence and overall survival.
The earliest study of aberrant DNA methylation in CRC was published in 1983 [17]. More recently, many studies have revealed that methylated alteration appeared to be crucial for CRC formation [18]. The most prevalent explanation was that hypermethylation caused the decrease of tumorsuppressor genes in cancers [19]. SorCS1 was aberrantly methylated in CRC tumors and adenomas, but it has not yet been identified as a tumor-suppressor gene. Using methylight primers covered one of the regions analyzed before, higher methylation level in tumor tissues than normal mucosa was confirmed in Chinese patients. On the other hand, in contrast to normal mucosa, we demonstrated that CRC tumor tissues exhibited a dramatic reduction of SorCS1 expression. In order to identify the role of hypermethylation in inactivation of SorCS1, Methylight and 5-aza treatment were performed. Consistent with the study on rectal cancer [14], the current data indicated that decreased SorCS1 expression might be due to hypermethylation. Taken together, gaining methylation and loss expression of SorCS1 may contribute to colorectal tumorigenesis. To date, absence of SorCS1 has not been reported to promote tumorigenesis. With regard to cellular and physiological functions of SorCS1, it is an important regulator of intracellular trafficking [20]. APP (amyloid precursor protein) processing is modulated by SorCS1 [13]. It's well known that SorCS1 is expressed in pancreatic islet cells and its expression is associated with glucose homeostasis and insulin secretion [21]. Although little is known about SorCS1 in cancers, some SorCS1 related genes, such as PDGF-BB, STAT3 and synaptic proteins Neurexin and AMPARs [22, 23] had been shown to be correlated with cancer development in many studies [24-27]. Therefore, in the present study, we paid attention to the interaction of SorCS1 expression and clinicopathological features. IHC results showed that expression of SorCS1 expression was inversely associated with age, serum CEA level and $\mathrm{pT}$ stage. These observations could be attributed to the tumor suppressor function of SorCS1 in CRC, which strongly suggested that SorCS1 was involved in the development and progression of CRC. However, the downstream mechanism of SorCS1 in CRC remains uncertain. In a previous study, it has been reported that expression of SorCS1 reduced the induction of pSTAT3 in HEK-293 cells, which indicated that SorCS1 may modulate the cancerrelated molecular system. Although SorCS1 could suppress the oncogenic molecules in some types of cell, further studies are needed to elucidate the function and underlying mechanism of SorCS1 in CRC.

The VPS10 domain containing receptor family contains five members, Sortilin, SorCS1, SorCS2, SorCS3 and SorLA. It was shown that VPS10P receptor Sortilin enhanced invasion of breast cancer cells [28] and proliferation of ovarian carcinoma cells [29]. SorCS2 was found to be upregulated in the group of CRCs with poor survival [30]. SorCS3 was demonstrated to be hypermethylated in gastric cancer [31]. Although the roles of all the family members have not been fully understood in cancer, it can be inferred 
Table 2. Univariate analysis of factors associated with CRC patient outcomes (OS and DFS, n=239).

\begin{tabular}{|c|c|c|c|c|c|c|}
\hline \multirow[b]{2}{*}{ Variables } & \multicolumn{3}{|c|}{ OS } & \multicolumn{3}{|c|}{ RFS } \\
\hline & HR & $95 \% \mathrm{CI}$ & p-value & HR & $95 \% \mathrm{CI}$ & p-value \\
\hline Age, years $(>60 / \leq 60)$ & 4.437 & $1.922-9.829$ & $<0.001$ & 1.561 & $0.876-2.781$ & 0.128 \\
\hline Gender (female/male) & 1.303 & $0.700-2.424$ & 0.402 & 0.710 & $0.401-1.258$ & 0.238 \\
\hline Histological grade (Poor / Moderate, High ) & 1.789 & $0.893-3.584$ & 0.096 & 0.9546 & $0.4483-2.033$ & 0.702 \\
\hline Mucinous (Yes / No) & 1.215 & $0.510-2.895$ & 0.659 & 1.145 & $0.572-2.289$ & 0.871 \\
\hline Location (Colon / Rectum) & 0.661 & $0.351-1.244$ & 0.196 & 0.650 & $0.369-1.145$ & 0.133 \\
\hline Tumor status (T3-4 / T1-2) & 2.277 & $0.892-5.813$ & 0.077 & 1.954 & $0.879-4.345$ & 0.094 \\
\hline Nodal status (N1-2 / N0) & 1.853 & $0.997-3.444$ & 0.048 & 2.686 & $1.531-4.711$ & $<0.001$ \\
\hline Vessel invasion (Yes / No) & 3.275 & $1.447-7.410$ & 0.009 & 2.469 & $1.109-5.496$ & 0.022 \\
\hline Perineural invasion (Yes / No) & 1.304 & $0.463-3.699$ & 0.614 & 2.048 & $0.919-4.567$ & 0.073 \\
\hline SorCS1 (High / Low) & 0.352 & $0.167-0.739$ & 0.004 & 0.415 & $0.221-0.781$ & 0.005 \\
\hline
\end{tabular}

HR greater and less than 1 indicate increased and decreased death risk, respectively; HR, hazard ratio; CRC, colorectal cancer; OS, overall survival; DFS, disease free survival

Table 3. Multivariate analysis of prognostic factors associated with overall and recurrence-free survival.

\begin{tabular}{|c|c|c|c|c|}
\hline \multirow{2}{*}{ Variables } & \multicolumn{2}{|l|}{ OS } & \multicolumn{2}{|c|}{ RFS } \\
\hline & HR (95\% CI) & p-value & HR (95\% CI) & p-value \\
\hline Age, years $(>60 / \leq 60)$ & $3.859(1.587-9.385)$ & 0.001 & & \\
\hline Nodal status (N1-2 / N0) & $1.568(0.835-2.945)$ & 0.162 & $2.522(1.426-4.462)$ & 0.001 \\
\hline Vessel invasion (Yes / No) & $3.093(1.349-7.089)$ & 0.008 & $1.950(0.865-4.396)$ & 0.107 \\
\hline SorCS1 (High / Low) & $0.422(0.199-0.892)$ & 0.024 & $0.415(0.220-0.780)$ & 0.006 \\
\hline
\end{tabular}

OS = overall survival; RFS = recurrence-free survival; $\mathrm{HR}=$ Hazard ratio; $95 \% \mathrm{CI}=95 \%$ confidence interval

A

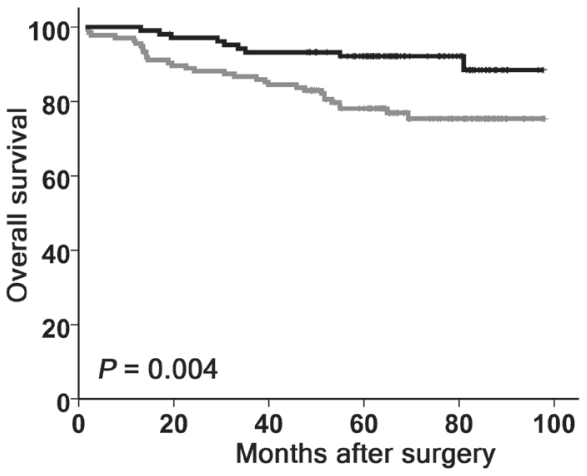

C

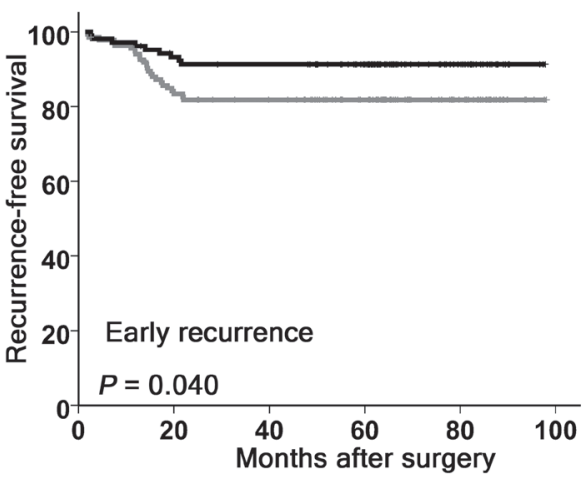

B

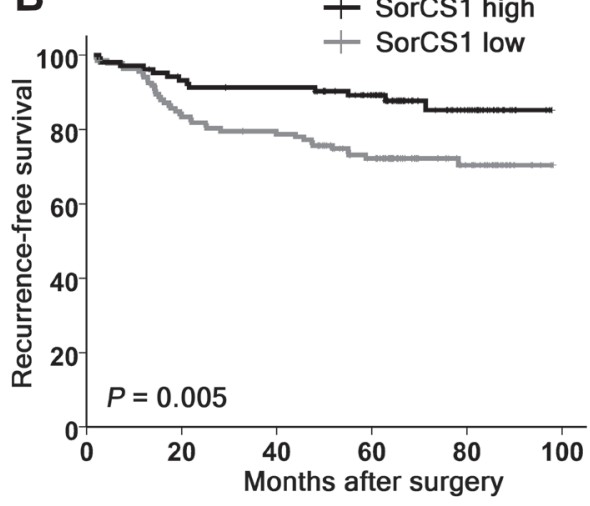

D

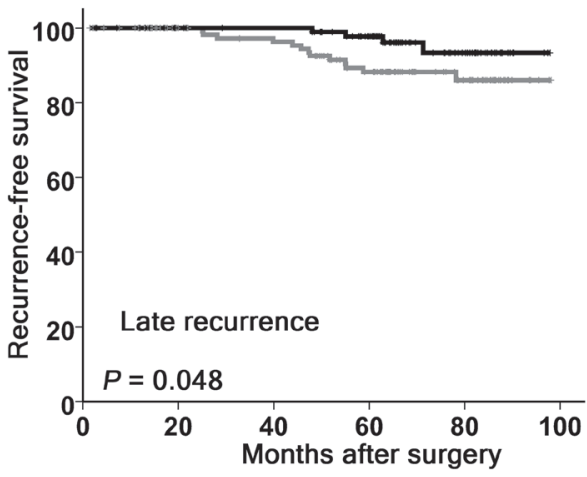

Figure 3. Kaplan-Meier estimates of overall survival (OS) and recurrencefree survival (RFS) of colorectal cancer patients according to SorCS1 expression. Patients with high expression of SorCS1 had a significantly better OS (A) and RFS (B) than those with low expression of SorCS1. Kaplan-Meier analysis of RFS for SorCS1 expression in early $(C)$ and late (D) recurrence group using a cut-off time of 2 years showed that the prognostic significance of SorCS1 expression was retained. 


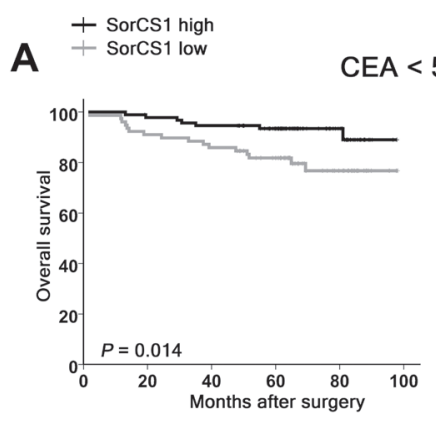

CEA $<5 \mathrm{ng} / \mathrm{ml}$

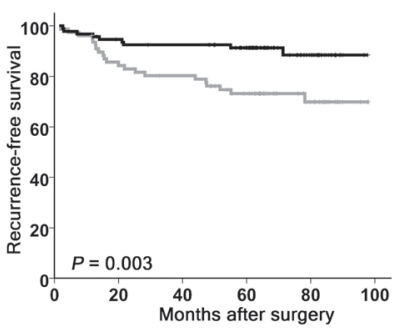

C

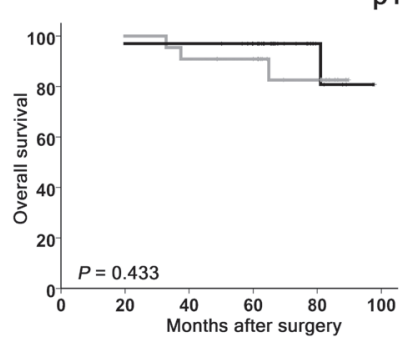

pT1-2

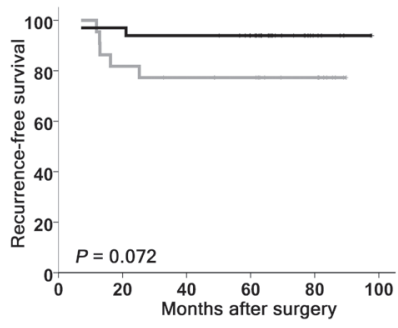

E

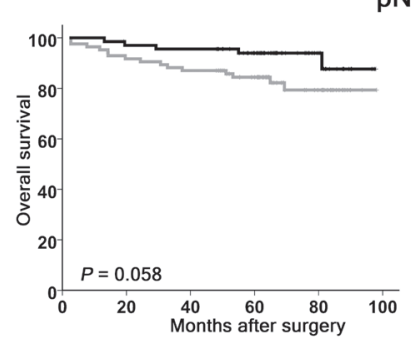

pNO

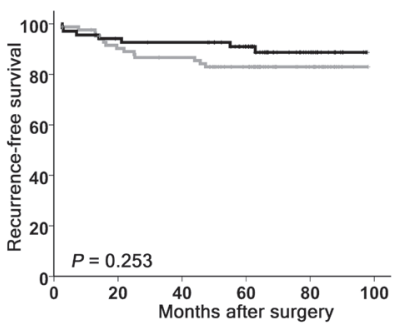

B

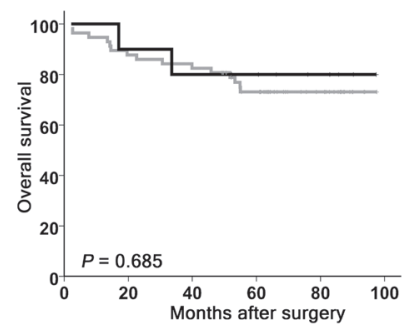

$\mathrm{CEA} \geq 5 \mathrm{ng} / \mathrm{ml}$

D

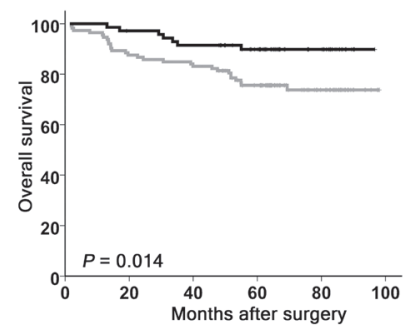

$\mathbf{F}$

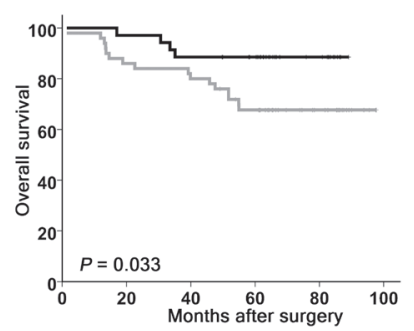

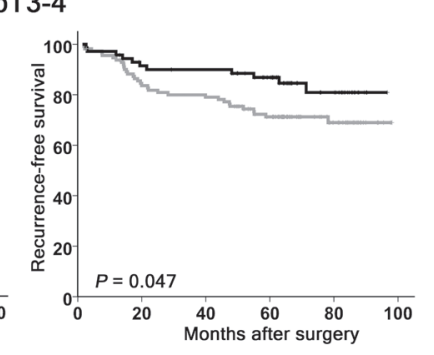

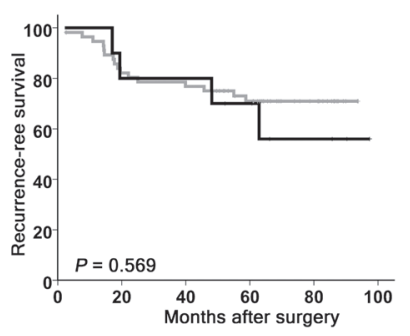

pT3-4

pN1-2

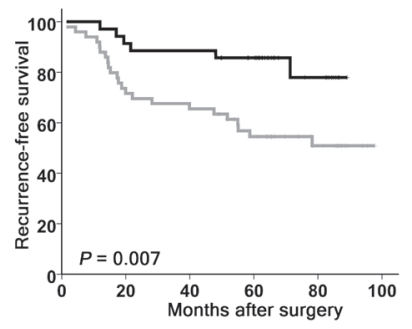

Figure 4. Stratified analysis of SorCS1 expression in predicting prognosis according to CEA level, local invasion depth (pT stage) and lymph node involvement ( $\mathrm{pN}$ stage). Patients with high expression of SorCS1 showed a significant benefit toward overall survival (OS) and recurrence-free survival (RFS) compared those with low expression of SorCS1 in the normal CEA level (A), pT3-4 (D) or pN1-2 (F) subgroup. No prognostic effect of SorCS1 expression was found in the high CEA level (B), pT1-2 (C) or pNo (E) subgroup.

from the previous studies that these proteins have important functions in tumor development. The possible tumor suppressor function of SorCS1 prompted us to explore its prognostic significance for CRC. Just as we expected, our results demonstrated that high SorCS1 expression was significantly associated with favorable OS and RFS of CRC patients. It seemed that SorCS1 was reliable prognostic biomarker. What's more, multivariate Cox analysis proved that SorCS1 expression was related to both of OS and RFS after consideration of other prognostic factors. It could be used as a potential prognostic biomarker to classify subtype of CRC patients who have increased risk of poor survival. In terms of early and late recurrence [32], the predictive potential of SorCS1 expression was evident in both of these groups, implying that low expression of SorCS1 was not only related to an aggressive phenotype, but also was involved in future cancer transformation.
In particular, further subgroup analysis revealed that higher expression of SorCS1 significantly improved OS and RFS of patients with pT3-4 or pN1-2 CRC but not patients with pT1-2 or pN0 CRC. This result may suggest that the effect of SorCS1 on CRC was more important in the patients with late stage. It's well known that CEA is a tumor marker for CRC [33] even its role in CRC prognostic prediction is controversial. The different predictive significance of SorCS1 in low and high CEA subgroups revealed its limited role as a predictive marker in patients with normal CEA level and it is consistent with the notion that CEA level was correlated with biology feature of CRC tumor.

In conclusion, to our knowledge, the present study is the first to report the clinical significance of SorCS1 in CRC patients. We provide evidence to demonstrate that SorCS1 was attenuated by hypermethylation in CRC and that downregulation of SorCS1 was associated with poor prognosis. 
Acknowledgements: The authors thank all of the patients who participated in this study. This work was supported by the National Basic Research Program of China (973 Program) (No. 2015CB554001, JW), the Natural Science Foundation of Guangdong Province (No. 2017A030313580), the Fundamental Research Funds for the Central Universities (Sun Yat-sen Univ ersity) (No. 17ykpy67), the National Natural Science Foundation of China (No. 81472257, YL; No. 81502022, XW), the Natural Science Fund for Distinguished Young Scholars of Guangdong Province (No. 2016A030306002, YL), the Outstanding Young Scholars Supported by Special Program to Cultivate Top Experts in Guangdong Province (No. 2015TQ01R454, YL), the Natural Science Foundation of Guangdong Province (No. 2016A030310222, HY; No. 2018A0303130303, HY), the Science and Technology Program of Guangzhou (No. 2014Y2-00160, JW), the Fundamental Research Funds for the Central Universities (Sun Yat-sen University) (No. 16ykpy35, XW) and National Key Clinical Discipline.

\section{References}

[1] SIEGEL RL, MILLER KD, JEMAL A. Cancer Statistics, 2017. CA Cancer J Clin 2017; 67: 7-30. https://doi.org/10.3322/ caac. 2138

[2] BRENNER H, KLOOR M, POX CP. Colorectal cancer. Lancet 2014; 383: 1490-1502. https://doi.org/10.1016/S01406736(13)61649-9

[3] CHEN W, ZHENG R, BAADE PD, ZHANG S, ZENG H et al. Cancer statistics in China, 2015. CA Cancer J Clin 2016; 66: 115-132. https://doi.org/10.3322/caac.21338

[4] EDGE SB, COMPTON CC. The American Joint Committee on Cancer: the 7th edition of the AJCC cancer staging manual and the future of TNM. Ann Surg Oncol 2010; 17: 1471-1474. https://doi.org/10.1245/s10434-010-0985-4

[5] YUAN BZ, DURKIN ME, POPESCU NC. Promoter hypermethylation of DLC-1, a candidate tumor suppressor gene, in several common human cancers. Cancer Genet Cytogenet 2003; 140: 113-117. https://doi.org/10.1016/s01654608(02)00674-X

[6] CHEN QW, ZHU XY, LI YY, MENG ZQ. Epigenetic regulation and cancer (review). Oncol Rep 2014; 31: 523-532.

[7] WEISENBERGER DJ, LIANG G, LENZ HJ. DNA methylation aberrancies delineate clinically distinct subsets of colorectal cancer and provide novel targets for epigenetic therapies. Oncogene 2018; 37: 566-577. https://doi. org/10.1038/onc.2017.374

[8] LUO Y, WONG CJ, KAZ AM, DZIECIATKOWSKI S, CARTER KT et al. Differences in DNA methylation signatures reveal multiple pathways of progression from adenoma to colorectal cancer. Gastroenterology 2014; 147: 418-429. https://doi.org/10.1053/j.gastro.2014.04.039

[9] HERMEY G, RIEDEL IB, HAMPE W, SCHALLER HC, HERMANS-BORGMEYER I. Identification and characterization of SorCS, a third member of a novel receptor family. Biochem Biophys Res Commun 1999; 266: 347-351. https:// doi.org/10.1006/bbrc.1999.1822
[10] CLEE SM, YANDELL BS, SCHUELER KM, RABAGLIA ME, RICHARDS OC et al. Positional cloning of Sorcs1, a type 2 diabetes quantitative trait locus. Nat Genet 2006; 38 : 688-693. https://doi.org/10.1038/ng1796

[11] HERMEY G, KEAT SJ, MADSEN P, JACOBSEN C, PETERSEN CM et al. Characterization of sorCS1, an alternatively spliced receptor with completely different cytoplasmic domains that mediate different trafficking in cells. J Biol Chem 2003; 278: 7390-7396. https://doi.org/10.1074/jbc. M210851200

[12] GOODARZI MO, LEHMAN DM, TAYLOR KD, GUO X, CUI J et al. SORCS1: a novel human type 2 diabetes susceptibility gene suggested by the mouse. Diabetes 2007; 56 : 1922-1929. https://doi.org/10.2337/db06-1677

[13] REITZ C, TOKUHIRO S, CLARK LN, CONRAD C, VONSATTEL JP et al. SORCS1 alters amyloid precursor protein processing and variants may increase Alzheimer's disease risk. Ann Neurol 2011; 69: 47-64. https://doi.org/10.1002/ ana. 22308

[14] HUA Y, MA X, LIU X, YUAN X, QIN H et al. Abnormal expression of mRNA, microRNA alteration and aberrant DNA methylation patterns in rectal adenocarcinoma. PLoS One 2017; 12: e0174461. https://doi.org/10.1371/journal. pone. 0174461

[15] HUANG AP, HUANG PZ, LUO YX, WANG B, LUO XM et al. CD 103 expression in normal epithelium is associated with poor prognosis of colorectal cancer patients within defined subgroups. Int J Clin Exp Pathol 2017; 10: 66246634.

[16] LUO Y, TSUCHIYA KD, IL PARK D, FAUSEL R, KANNGURN $S$ et al. RET is a potential tumor suppressor gene in colorectal cancer. Oncogene 2013; 32: 2037-2047. https://doi.org/10.1038/onc.2012.225

[17] FEINBERG AP, VOGELSTEIN B. Hypomethylation distinguishes genes of some human cancers from their normal counterparts. Nature 1983; 301: 89-92. https://doi. org/10.1038/301089a0

[18] TOYOTA M, HO C, AHUJA N, JAIR KW, LI Q et al. Identification of differentially methylated sequences in colorectal cancer by methylated CpG island amplification. Cancer Res 1999; 59: 2307-2312.

[19] BAYLIN SB, JONES PA. A decade of exploring the cancer epigenome - biological and translational implications. Nat Rev Cancer 2011; 11: 726-734. https://doi.org/10.1038/ $\operatorname{nrc} 3130$

[20] HERMEY G. The Vps10p-domain receptor family. Cell Mol Life Sci 2009; 66: 2677-2689. https://doi.org/10.1007/ s00018-009-0043-1

[21] SCHMIDT V, WILLNOW TE. Protein sorting gone wrong-VPS10P domain receptors in cardiovascular and metabolic diseases. Atherosclerosis 2016; 245: 194-199. https://doi. org/10.1016/j.atherosclerosis.2015.11.027

[22] LARSEN JV, HERMEY G, SORENSEN ES, PRABAKARAN T, CHRISTENSEN EI et al. Human sorCS1 binds sortilin and hampers its cellular functions. Biochem J 2014; 457: 277-288. https://doi.org/10.1042/BJ20130386 
[23] SAVAS JN, RIBEIRO LF, WIERDA KD, WRIGHT R, DENARDO-WILKE LA et al. The Sorting Receptor SorCS1 Regulates Trafficking of Neurexin and AMPA Receptors. Neuron 2015; 87: 764-780. https://doi.org/10.1016/j.neuron.2015.08.007

[24] MANZAT SAPLACAN RM, BALACESCU L, GHERMAN C, CHIRA RI, CRAIU A et al. The Role of PDGFs and PDGFRs in Colorectal Cancer. Mediators Inflamm 2017; 2017: 4708076. https://doi.org/10.1155/2017/4708076

[25] JOHNSON DE, O'KEEFE RA, GRANDIS JR. Targeting the IL-6/JAK/STAT3 signalling axis in cancer. Nat Rev Clin Oncol 2018; 15: 234-248. https://doi.org/10.1038/nrclinonc. 2018.8

[26] SUN HT, CHENG SX, TU Y, LI XH, ZHANG S. FoxQ1 promotes glioma cells proliferation and migration by regulating NRXN3 expression. PLoS One 2013; 8: e55693. https://doi. org/10.1371/journal.pone.0055693

[27] LIU KH, YANG ST, LIN YK, LIN JW, LEE YH et al. Fluoxetine, an antidepressant, suppresses glioblastoma by evoking AMPAR-mediated calcium-dependent apoptosis. Oncotarget 2015; 6: 5088-5101. https://doi.org/10.18632/oncotarget.3243

[28] ROSELLI S, PUNDAVELA J, DEMONT Y, FAULKNER $S$, KEENE $S$ et al. Sortilin is associated with breast cancer aggressiveness and contributes to tumor cell adhesion and invasion. Oncotarget 2015; 6: 10473-10486. https://doi. org/10.18632/oncotarget.3401
[29] GHAEMIMANESH F, AHMADIAN G, TALEBI S, ZARNANI AH, BEHMANESH M et al. The effect of sortilin silencing on ovarian carcinoma cells. Avicenna J Med Biotechnol 2014; 6: 169-177.

[30] ABDUL AZIZ NA, MOKHTAR NM, HARUN R, MOLLAH MM, MOHAMED ROSE I et al. A 19-Gene expression signature as a predictor of survival in colorectal cancer. BMC Med Genomics 2016; 9: 58. https://doi.org/10.1186/s12920016-0218-1

[31] SCHNEIDER BG, MERA R, PIAZUELO MB, BRAVO JC, ZABALETA J et al. DNA Methylation Predicts Progression of Human Gastric Lesions. Cancer Epidemiol Biomarkers Prev 2015; 24: 1607-1613. https://doi.org/10.1158/10559965.EPI-15-0388

[32] RYUK JP, CHOI GS, PARK JS, KIM HJ, PARK SY et al. Predictive factors and the prognosis of recurrence of colorectal cancer within 2 years after curative resection. Ann Surg Treat Res 2014; 86: 143-151. https://doi.org/10.4174/ astr.2014.86.3.143

[33] GOLD P, FREEDMAN SO. Demonstration of Tumor-Specific Antigens in Human Colonic Carcinomata by Immunological Tolerance and Absorption Techniques. J Exp Med 1965; 121: 439-462. https://doi.org/10.1084/jem.121.3.439 